\title{
The Effectiveness of Inquiry-based Learning on Middle School Students' Mathematics Reasoning Skill
}

\author{
By Ceylan Şen*, Zeynep Sonay A $Y^{\dagger} \&$ Gürsel Güler ${ }^{t}$
}

\begin{abstract}
This study investigated the effectiveness of inquiry-based learning (IBL) approach in ratio and proportion on the mathematics reasoning skill of seventh-grade students. The study was carried out in a seventh-grade mathematics course in a middle school located in the Central Anatolia region of Turkey during the 2016-2017 academic year. The IBL content was prepared and implemented about the ratio and proportion topics on which the reasoning skill is effective in the 7 th grade curriculum. The IBL teaching implementations were conducted with 30 seventh grade students, but nine students, who represented different math achievement levels, were selected for the study's analysis. Course video recordings, worksheets, student interviews, and diaries were used as data collection tools. The results showed that the students' predictive, explanation, generalization and justification skills emerged as indicators of reasoning skill. Students made different predictions and generalizations based on their existing knowledge and they developed solutions to problems using different strategies in IBL process. According to these findings, it was concluded that students' reasoning skill were effective during IBL.
\end{abstract}

Keywords: Inquiry-Based Learning in Mathematics (IBL-M), Reasoning skill, Ratio and proportion, Middle school students

\section{Introduction}

IBL is a training strategy in which students develop their own methods and practices in structuring scientific knowledge. IBL is a problem-solving approach used by learners from early childhood which aims to enhance their inquiry and reasoning skills within cause-and-effect relationships to learn concepts and develop in-depth understanding (Keselman, 2003). IBL in mathematics education (IBL-M) involves an instructional process in which semi structured questions involving real-life problems are asked to encourage learning and stimulate curiosity in students (Blair, 2008). IBL-M emphasizes the importance of feedback while constructing new mathematical ideas.

The National Council of Teachers of Mathematics (NCTM, 2000) emphasizes the importance of mathematical problem-solving in the IBL-M process in which students are engaged in mathematical argument-making, assumptions, questionformulating, and solution development for realistic problems. Therefore, IBL-M is student-focused, inquiry-based, and problem/ question-based, and the use of communication, cooperation, and reflection skills are essential in the instructional process. IBL-M offers the opportunity to generate and create new perspectives on

*Assistant Professor, Yozgat Bozok University, Turkey.

${ }^{\dagger}$ Assistant Professor, Hacettepe University, Turkey.

${ }^{\star}$ Associate Professor, Yozgat Bozok University, Turkey. 
mathematical problems and content by giving students questions in the context of the curriculum, starting from their previous experience and experimenting with multiple solutions (Chapman, 2011). The IBL mathematics classroom is based on the construction of mathematical rules, concepts, and principles by students beyond the direct presentation of mathematical concepts and processes by the teacher. IBL-M can help students to develop alternative mathematical explanations through interaction with their teacher and peers, the creation of sociomathematical norms, and the free circulation of ideas in the classroom. In IBL-M, students are asked questions such as "If happens, what should we do?" to encourage them to question and explore (Slavit \& Lesseig, 2016). Utilizing such questions in the teaching process may improve students' ability to recognize and adopt mathematical concepts and rules. Many studies (e.g. Chapman, 2011; NCTM, 2000; Stein, Engle, Smith, \& Hughes, 2008) have indicated that IBL-M is effective in solving non-routine problems, as well as in researching and exploring mathematical rules and concepts. Kwon, Park, \& Park (2006) emphasized that IBL-M can develop students' in-depth mathematical understanding and mathematical thinking and positively contribute to their problem-solving and creativity skills. However, despite having been shown to have positive effect on mathematics instruction, the IBL-M approach is still under-utilized by mathematics teachers (Jacobs et al., 2006). Among the common reasons why teachers do not apply the IBL approach in their mathematics lessons include the lack of time for students to explore and research due to exam preparation demands, a lack of independent working skills among students, and the inadequacy of students (Engeln, Euler, \& Maass, 2013). Furthermore, Handal (2003) found that many teachers chose not to use IBLM because of their belief that mathematics is made up of rules and principles, and thus mathematical knowledge is based on memorization rather than exploration.

\section{Reasoning Skill in IBL-M}

The effectiveness of students' reasoning skill can emerge during in IBL-M process. Schoenfeld (1992) definers reasoning skill "the ability to use mathematical tools in mathematicalisation and abstraction and understanding mathematical structure using these tools" (p. 1). In addition, NCTM (2009) defined reasoning as the "process of conclusion based on evidence or assumptions" (p. 56). According to many researchers (Kasmer \& Kim, 2011; Martin \& Kasmer, 2010), reasoning skill involve analysing a problem, choosing a strategy for its solution, applying the strategy to find a solution to the problem, and supporting the process through their thinking in this respect, providing support for the development of reasoning skill is an important element of meaningful mathematics instruction.

Reasoning skill is a discussion tool which is carried out with the aim of making inferences based on logic (Sperber, 2000). Based on this definition, justification through discussion, evidence-based explanation, argument evaluation and persuasion are indicators of reasoning skill (Mercier \& Sperber, 2011). In a discussion environment, explanations based on justification are offered for the 
acceptance of ideas and thoughts by the community and there is an effort to persuade the community. A common generalization or group thoughts with different opinions are revealed by critical evaluation of the shared views and thoughts. IBL-M takes the form of classroom discussions and educational strategies in which students' thought processes are supported in seeking solutions to problems to discover mathematical concepts and, finally, make generalizations (Hähkiöniemi, 2013).

For the present study, ratio and proportion were chosen as the topic for the IBL-M instruction. The importance of ratio and proportion were emphasized by NCTM (2000), which stated that "students throughout the fifth to eighth grades are given reasoning skill developments and that a great effort should be made to develop this skill" (p. 144). Many students have difficulty internalizing the concepts of ratio and proportion (Baron, 2010). Lanius and Williams (2003) emphasized the importance of understanding ratio and proportion, as they form the basis of understanding many concepts in mathematics and other disciplines. Students who encounter problems with ratio and proportion have the opportunity to develop different problem-solving strategies, as well as create common solutions (Shield \& Dole, 2008). It follows that the teaching of ratio and proportion presents the students with the opportunities to be engaged in a discussion environment and to express their thoughts considerably. Furthermore, with this topic, it is necessary for students to shift from addictive comparison to multiplicative comparison.

There are many real-life problem situations related to ratio, proportion, and proportioning. Ratio and proportion are related to many areas of everyday life such as drawing, trading, converting currencies, adjusting and following recipes, among others (Tourniaire \& Pulos, 1985). It has been suggested that real-life problems be used to teach ratio and proportion, and that students should be encouraged to use different strategies and develop written and oral explanations (Ilany, Keret, \& BenChaim, 2004). In this way, solving with different strategies of real-life problems can contribute to the development of students' reasoning skills.

Ministry of National Education (MoNE, 2009) adopts the constructivist approach in mathematics education. The present study thus aims to demonstrate the effectiveness of the IBL-M approach, on which the constructivism emphasis, in improving students' reasoning skill in mathematics. For this purpose, the present study focused on the teaching of ratio and proportion to seventh-grade mathematics students to examine the effectiveness of IBL-M on their reasoning skill. The study thus posed the following research question:

1. How effective is the IBL-M approach in the teaching of ratio and proportion on students' reasoning skill?

2. What are the views of students on the effectiveness of the IBL approach in mathematics instruction? 


\section{Methodology}

\section{Study Design}

This research model is based on qualitative research methods that provide indepth analysis of the study (Bogdan \& Biklen, 1998). The present study used a case study design. Case studies are appropriate in the examination of special cases in a certain context and include in-depth research on specific phenomena such as programs, people, processes, or social groups in education (Creswell, 2008).

\section{Participants}

The study participants consisted of nine students who had different levels of mathematics abilities among 30 seventh-grade students studying at a middle school in the Central Anatolia region of Turkey during the 2016-2017 academic year spring semester. According to the classroom teacher's opinion, the nine participants were selected based on their varying mathematical achievement levels to provide diversity for the study. With maximum variation sampling, it can be show up whether there are common phenomena between diversified situations and different dimensions of problem (Yıldırım \& Şimşek, 2013).

After informing the students about the contents of the study, volunteer students were selected as participants. To assess changes in the students' reasoning skill the participants' work was observed and interviews were conducted. Each participant was assigned a pseudonym by the researchers to ensure confidentiality.

\section{Study Instruments}

The present study used qualitative data collection methods such as interviews, observations, and documents. The study instruments included interview forms, observation forms, and worksheets. In this way, it was possible to prevent, compare, and confirm the loss of data as many different data sources were included. Triangulation of the study data was achieved with the use of different qualitative data collecting tools (Guba \& Lincoln, 1982).

Interviews. In the study, semi-structured interviews with students were conducted to determine the extent of changes in their reasoning skill during the IBL-M. The interview form was created by the researchers based on the related literature (Slavit \& Lesseig, 2016; Brown \& Walter, 2014). The prepared draft form content was sent to three mathematics education experts to determine the scope, content, and suitability of the form. The draft form was prepared for pilot implementation to obtain the advice of experts. Interview content included questions regarding IBL-M implementation, activities used, and the evaluation of individual structures in the study's implementation processes.

Following the completion of the implementations, pilot interviews were conducted to determine the views of students. After the pilot implementation, some questions were changed and the final version of the interview form, in which 
eight semi-structured questions were included, was provided (Appendix-1). The actual interviews were also carried out following the same process used in the pilot implementation.

Interviews were completed two days after the end of the study implementation. The interviews were conducted between the researcher and the participants individually, so that the students would not be affected by each other and would share their views sincerely. The interviews were held in a quiet and disturbance-free environment in vice principal's office with an "interviewing" sign hung on the door to prevent interruptions. Each interview lasted about 15-20 minutes and was audio recorded. The participants were informed prior to the interviews that they would be audio recorded and that their identity would be kept confidential. Each participant consented to participate in the interview. After, the interviews recordings were transcribed, the participants were asked to confirm whether the recording understood correctly.

Observations. The semi-structured observation form was filled in by a nonparticipant observer throughout the study implementation process, because the researcher was busy teaching and observing the participants. The observation form was developed by the researchers and was first applied in a pilot practice session to obtain the opinions of experts; changes were made after. The observation form was prepared based on the development of reasoning skill described in the MoNE (2013) Middle School Mathematics Curriculum. Using the observation form, it was possible to record the data in an objective manner. Thus, it was provided with the support of the data through observations and opinions as well as the help of the assistant teacher's observations.

Documents. Students' worksheets were used in the present study as data collection tools. The worksheets consisted of sections that guided students in each activity in the IBL-M process and included questions for them to answer. The student worksheets also included homework questions.

\section{Data Analysis}

Data were obtained in two ways; data from video recordings during IBL-M and interviews with participants at the end of the IBL-M process. Below is a detailed description of the analysis of the data obtained in two ways.

Video Recordings Analysis. During IBL-M, problem solving activities were carried out with the students. Problem solutions and explanations of students were evaluated within the scope of reasoning skill in this process. This implementation process was recorded with video recording. The solutions, explanations and discussion process of the students to the problems were analysed within the scope of reasoning skill.

The data were then classified under the headings of reasoning skill, as per the aim of the present study. Literature is examined in the formation of these skills and sub-skills and skill list has been revealed. Reasoning skill include predicting and 
inferring; defending the accuracy and validity of the inference; presenting data in logical generalizations; and informal proofing such as recognizing mathematical relationships and establishing cause-effect relationships, assumptions, and generalizations (Stylianides \& Stylianides, 2009). In this study, student reasoning skill were analysed and evaluated according to this framework.

The analysis of the data thus obtained in accordance with the predetermined themes is defined as descriptive analysis (Yıldırım \& Şimşek, 2013). For this purpose, a four-step path was followed. Firstly, literature on reasoning skill has been searched and analysis framework related to skills and sub-skills has been formed. Then, the data analysed from the data set were processed into the identified skills and sub-skills. At this stage, the obtained data for reasoning skill was coded according to their common characteristics, and the codes are listed. The codes were categorized into the categories that emerged. Coding was completed by two different researchers and provided a comparative end-of-view consensus. To provide descriptive support for the submitted codes and categories, direct citations from participant opinions, and worksheets were included. The analysis of the content was directly supported by descriptive explanations.

Interview Analysis. At the end of the IBL-M, individual interviews were conducted with the students to evaluate the IBL-M process. The data obtained from the individual interviews were analysed through content analysis and the findings were supported descriptively with direct quotations. Content analysis is a technique that enables indirect analysis of human behaviours that cannot be directly observed and cannot be measured (Fraenkel \& Wallen, 2009). The audio and video recordings obtained from the individual interviews were converted to written computer documents. In the individual interviews conducted after IBL-M, a student was coded together with a researcher specialized in mathematics education. Coding for other students was analysed separately by expert educator and researcher; codes and categories were compared and mutually negotiated.

\section{The IBL-M Process in Ratio and Proportion Instruction}

The course content was prepared by the researchers based on the curriculum content for the topic of ratio and proportion. In addition, the creation of content was modelled after the sample content obtained from Van de Walle, Karp and Bay-Williams (2013) and related literature. To determine the appropriateness of the course content in terms of the curriculum, IBL-M, and the students' learning needs, an evaluation form was prepared based on the related literature and then sent to three researchers who are experts in mathematics education to obtain their opinions. The lesson contents were arranged according to the experts' opinions, and 10 one-hour sessions were planned. The IBL-M ratio and proportion instruction was implemented during the spring semester of the 2016-2017 academic year following the completion of the pilot study.

The researcher assumed an observational role and taught the lessons. Furthermore, one assistant teacher was involved in the study as an assistant to assist with video recording and taking photos during the classes. At the end of the 
IBL-M implementation, interviews were held to determine the students' views regarding IBL-M. During IB-M, video recording was used to record all the data and student behaviours. The camera was placed at the rear of the classroom to prevent the students from changing their natural classroom behaviours. The IBL$M$ process should include the following elements:

- The identification of students' prior knowledge

- The creation of a learning environment in which students can share their ideas with one another

- The fostering of students" "why, what, how, etc." questions

- The evaluation of student explanations using alternative explanations from the teacher

- Efforts to develop alternative solutions to a problem

During the study implementation, each student worked independently and created their own' solutions for each problem. The students were asked to share their solutions with their peers and provide justifications for their answers. Throughout this process, the researcher asked the students to elaborate on why, what, and how they chose to solve the problems. An outline of the IBL-M implementation process from the first lesson is provided below.

The IBL-M Implementation Process during the First Session. In the first session, the students were given the following instructions:

- Instead of receiving direct descriptions and explanations, the students should focus on their relationships among concepts.

- Individual and group work will be done

- The activity, worksheets, and reflective logs will be included in the lesson

- Everyone's ideas are important, and everyone should engage in discussion rather than be concerned about right and wrong answers

After the above instructions were given, a discussion environment was created by asking the class questions to assess their existing knowledge and establish a comfortable environment in which they could express their views freely. Student answers to the question "What is ratio?" were written on the board. The views of the students were revealed additive or multiplicative comparison with this question. Then, the students were asked to give a general explanation of proportion. Then, meaningful problems that related to the students' daily lives were presented.

Example 1. Affixing images of apples, oranges, and watermelons to the blackboard, the teacher stated, "A farmer gathered ripe apples, oranges, and watermelons from the field and put them in the basket." The teacher then asked about the meaning of the expressions "apples to oranges ratio" or "apples to watermelon," and what their mathematical representations would be. Then, "why" questions related to the representations were posed. The students were asked to make explanations and justifications. 
How the mathematical representation of the rate is expressed, how many different representations can be made ${ }^{\frac{a}{b}}$, and the $\mathrm{a} / \mathrm{b}$ and $\mathrm{a}: \mathrm{b}$ representations were mentioned. For example, the apple to orange ratio is said to be the simplest notation, as 8/6. It is emphasized that the ratio is constant and different multiples express the same ratio. For proportion, the simplest notation simplification is used. Through this process, the students learned about ratio and proportion.

Example 2. By affixing a picture of two persons to the board, in which one person is tall $(185 \mathrm{~cm})$ and the other is short $(110 \mathrm{~cm})$, the students are asked to describe the proportions.

The teacher attempted to associate the simplification operations used in Example 1 with the problem described in Example 2. For this purpose, the students were asked questions such as "How can the proportions be written in their simplest form?"

\section{Findings}

\section{The Effectiveness of IBL-M on Students' Reasoning Skill}

Ratio and proportion problems necessitate the development of reasoning skill and involve the transition from additive comparison to multiplicative comparison. Table 1 displays the analysis of the students' reasoning skill observed at the beginning and end of the IBL-M implementation process, taken from all classroom observations.

Table 1. Process Analysis for the Development of Reasoning Skill

\begin{tabular}{|l|c|}
\hline Beginning of IBL-M & Process IBL-M \\
\hline Additive comparison & Multiplicative comparison \\
\hline Multiplicative comparison & Convincing \\
\hline & Exploring \\
\hline & Making connections \\
\hline & Justification \\
\hline & Generalizing \\
\hline & Systematizing \\
\hline
\end{tabular}

Analysing the class discussions during different sessions of the IBL-M training, it was found that the students' reasoning skill improved during the process. It was observed that the students used justifications for their solutions, which contributed positively to their reasoning skill development. This result was supported by the information provided in the assistant teacher observation forms. The observations showed that the students improved in predicting, establishing cause and effect relationships, explaining and justifying, generalizing, and abstracting. The following is an example from the class discussion of the first session: 
Researcher (R): A farmer gathered ripe apples, oranges, and watermelons from the field and put them in the basket. What is the ratio of apples to oranges and watermelons to apples?

Samet: There are mostly apples, then oranges, and last watermelons. Berk: Teacher, when we say proportion, do we look at the differences between the items?

Ali: When we say "ratio," we are dividing, so we use a slash (/).

Fatih: Yes, when we are asked for the ratio, we write the first one on the bottom, and the second one on the top.

Mehmet: No, I think it is the opposite: the first is on the top, and the second one is on the bottom.

$\boldsymbol{R}:$ Yes, when we are asked to find the ratio, we write the first one on the bottom, and the second one on the top.

Mehmet: In this way our teacher taught us for not to mix them up.

Most students thought that finding the ratio required addition or subtraction. It can be said that the students in the direction of the answers are inadequate about the ratio, proportion and the reasoning skill. At the same time, it was seemed that students' answers were informed by their teacher's prior instruction. Thus, it was observed that students were lack of conceptualization of ratio as well as their multiplicative comparison. For this reason, multiplicative comparison was first emphasized, and then the transition from ratio to proportion was achieved. Next, to assess the additive and multiplicative comparison of the students, open-ended, real-life problems were created, and a class discussion ensued. Below, an excerpt from the discussion transcript of the second session is provided.

Question: What can you say about the numbers of girls in the two groups? (see Figure 1)

Figure 1. Question's Visual

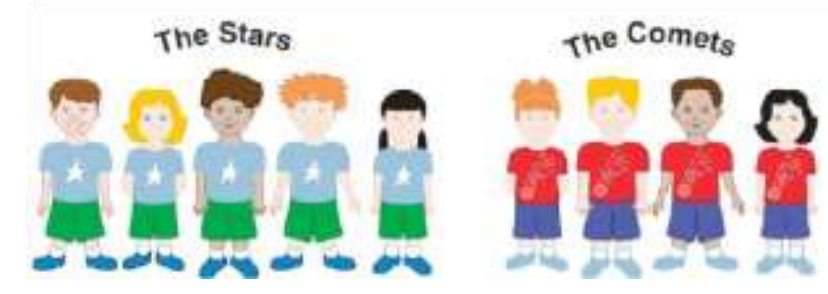

Ali: Teacher, do we say which group has the most girls, or do we compare the groups?

Burcu: If we are asked in which group there are morelfewer girls, we would only have to look at the numbers, then we would have said 2 since the number is equal in both groups.

Idil: If the number of girls is more than the number of the boys, we could say 3-2 = 1 for the stars group and 4-2 = 2 for the coments group. 
It can be seen from the transcript that when the students tried to provide explanations, they were not sure of whether to use addition or multiplication in their solutions. Below, the transcript from this class discussion continues:

R: In both cases, the number of girls is equal, so why did you solve it like this?(see Fig. 2)

Suna: Yes, the numbers of girls in the two groups are equal, but we are supposed to make comparisons. So, if the ratio between the first and second group is $2 / 5$, there are 2 girls in the second group but 2 girls out of 4 people. So, the girls' ratio in the second group is $2 / 4$.

Figure 2. Suna's Response

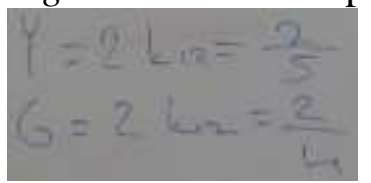

Researcher: But I did not say the ratio of the number of girls to the total number of individuals in the group.

Asll: If you asked for the ratio of girls to boys, we would write 2/3 for the first group and 2/2 for the second group.

Fatih: Teacher, whether we rate the number of girls to the number of boys in the group or to the total number, it is higher in the second group. Nothing changes.

The students' responses to the example problem in the second session show that they had already developed some multiplicative reasoning skills, and they realized that proportion involves comparison and not addition. At the same time, it seems that they had discovered the concept of ratio constant in an informal way.

Inadequate and appropriate strategies for the use of multiplicative comparison to elicit students' ideas in the IBL-M process are presented in an excerpt from the transcript of the fourth session below.

Question: Mr. Short has a friend named Mr. Tall. When the height of the Mr. Short was measured using paperclips, it was found that he was 6 paperclips tall. When Mr. Tall and Mr. Short are measured using buttons, it was found that Mr. Tall was 6 buttons tall and Mr. Short was 4 buttons tall. According to this, how tall is Mr. Tall in paperclips? 
Figure 3. Sample Student Responses
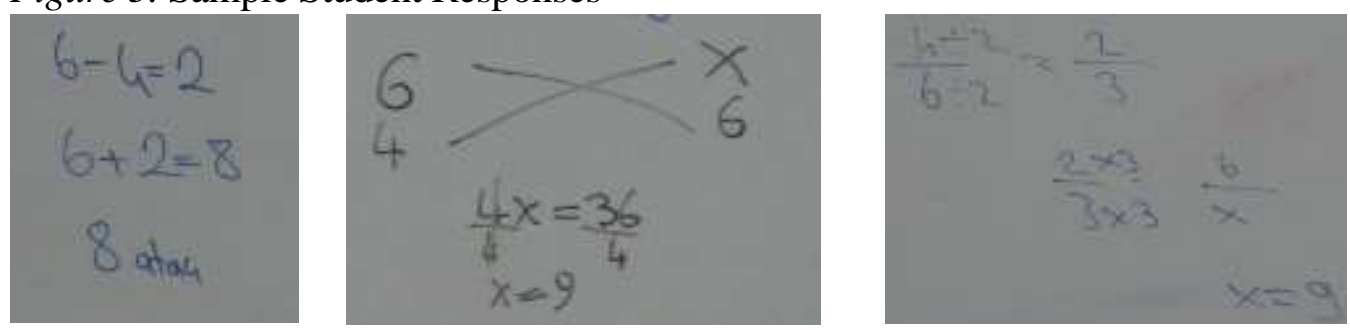

Before strategies were presented directly by the teacher, it was observed that the students were thinking critically, criticized different solution methods for ratio and proportion, and justified their chosen solutions in Figure 3. Some student solutions given during the class discussion are displayed below.

Suna: When we look at the height of Mr. Short, it increased by 6-4 = 2. So, $M r$. Tall's height will also increase by 2 and will be $6+2=8$.

Mehmet: The first one is measured with paper clips and the second one is with buttons. So, it is not the same. We have to do it this way, because the two situations are different.

Samet: There is a comparison of Mr. Short and Mr. Long here, so it is a ratio. Ali: There is also a comparison between the first case (paper clip measurement) and the second case (button measurement). So, proportions should be used.

Aslı: It is measured with the paperclips at first, then with buttons. Mr. Short was 6 paperclips and 4 buttons in height, so the value is reduced. Then, $M r$. Tall, who measured 6 buttons, should be a larger number when measured with paperclips.

From the transcript excerpt above, it can be noted that the students were thinking critically and using reasoning skill. Student explanations and statements using the cross-multiplication strategy are presented below.

$\boldsymbol{R}:$ What does the cross you drew here mean?

Burcu: It means that we cross-multiply.

R: Why do we cross-multiply? What is the logic behind it?

Burcu: If the question is about proportion, we write 6/4 for Mr. Short as the length in paperclips and buttons, and the ratio for Mr. Tall as $x / 6$. That is $6 / 4=x / 6$. We then cross-multiply to get the solution.

The student's explanation shows appropriate strategy-use and the justification of his thinking in the context of cause-effect relationships; furthermore, the student displayed the ability to make generalizations. A student's statement related the use of the unit rate strategy is presented below.

Mehmet: When comparing two things, we were writing the ratio. In this question, there is a measurement with paperclips and buttons. So, I wrote the lengths of the buttons/paperclips, 4/6. This reduces to 2/3 in its simplest form. 
Since the ratio does not change, I wrote $2 / 3=6 / x$, then cross-multiplied to get $x=9$.

The above statement shows that the student solved the problem by going beyond simple proportion and calculating the product of the proportion. Thus, many different solution strategies can be explored by the students by trying different ways of solving a problem, even if the definition or usage of the equivalent fraction strategy is not known by the student.

Through reasoning skill development, it was aimed to establish proportionality without proportioning in the fifth and sixth sessions, which were intended to foster students' reasoning skill development. For this purpose, problems with direct proportions were given first. The transcript excerpt below shows student reasoning using direct proportions.

Question: Arda, who went to an amusement park, paid 6 f for 3 balloons. So, how much does it cost to buy 24 balloons?

Figure 4. Sample Student Responses
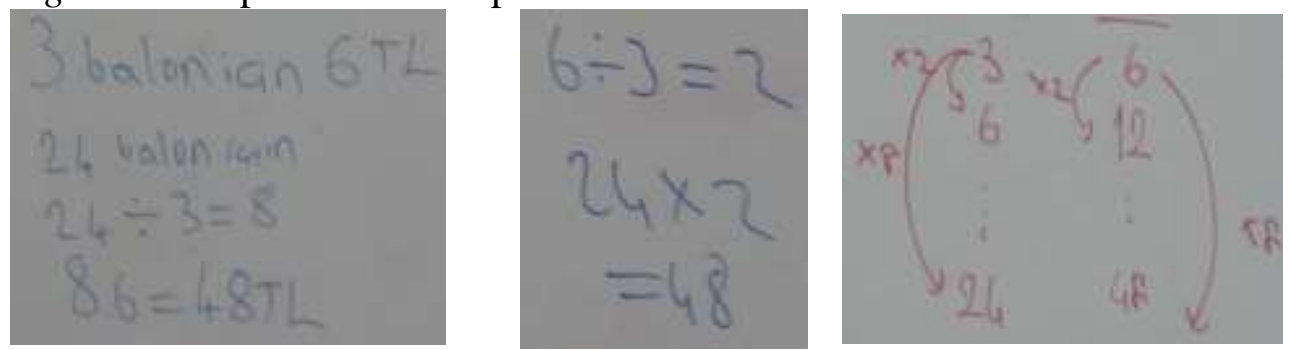

As shown in Figure 4, the students used different solutions to arrive at the correct answer. Afterwards, different solutions were demonstrated by the students on the board and they were explained by the teacher.

Even though the definition of direct proportion was not given, the students demonstrated an awareness of this in the solutions they gave for the problem and showed an understanding of the logic of direct proportion.

Mehmet: I divided the price by the number of balloons $(6 / 3=2)$. So, I found that the price of one balloon was $2 \mathrm{E}$. Then, I calculated that $24 \times 2=48 \mathrm{E}$. So, 48 is needed to buy 24 balloons.

Therefore, although no problem-solving strategy was given to the students, they discovered many ways to solve the problem on their own. In this way, the students discovered the existence of the proportionality constant. At the same time, it seems that the students realized the solution from the unit rate strategy.

In the sixth session, the students were first introduced to the expression " $x$," which had not yet been taught in the class. Problems with an unknown were then presented to the students and their solutions were examined. 
Question: The ratio of two numbers is $3 / 4$. Since the sum of these numbers is 98 , what is the smallest number?

Figure 5. Sample Student Responses
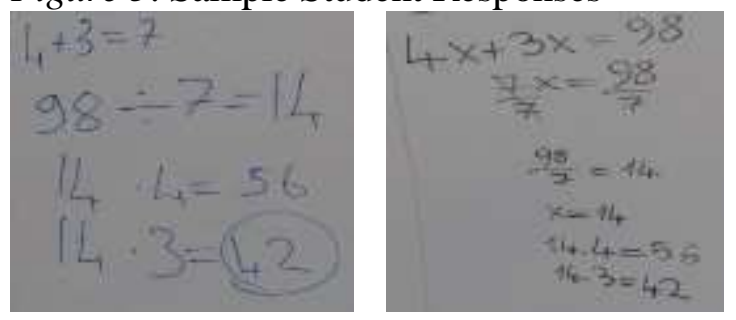

Ali: I thought that, if these numbers were not a ratio that is 3 or 4, then the sum would be 7.

Samet: The numbers are not mentioned here, but the ratio is. So, I think addition is not suitable here.

Ali: Here, the total is not 7, it is 98, and 14 times the sum of these numbers is $(98 / 7=14)$. That is, if 14 times the sum is calculated, and 14 times those numbers are also calculated, then the answer can be found by taking 14 times 3 as $14 \times 3=42$, and 14 times 4 as $14 \times 4=56$.

Berk: I do not understand this way.

$\boldsymbol{R}:$ So, what are we supposed to do, as your friends are not convinced about the solution?

Ali: Then I'll show you that it's true by reversing. Look, (turning to his friend), now we've got the products and we found the numbers 42 and 56. Rate them, 42/56 = 3/4, did you see? I am correct.

In the Figure 5, it seems that the student did the numeration without using the unknown and solved the problem. At the same time, the student justified his answer by explaining the reasons to his friends who did not understand the solution. The student used the word "proof" to convince his friend that his solution was correct. Although the process that the student used is not considered to be formal proof, it involved the backward strategy.

Burcu: When the ratio of the two numbers is given, it means that the simplest form is 3/4. That is, one is a product of 3 and the other is a product of 4. But the products of 3 and 4 are the same, so it is simplified. Then, we call one $3 x$ and the other $4 x$. Their total is 98. I wrote $4 x+3 x=98$. I multiplied by $7 x=$ 98, unknown 7. Then, to find the unknown, we have to divide both sides of the equation by 7. I found that $x=14$; that is, 14 times 3 and 4 .

In his solution using $\mathrm{x}$, the student showed the ability to use abstract thinking. In this sense, the result of the instructional process addressed the students' higherorder thinking skills. It was thus observed that even though the students were not provided with rules and methods directly, they were able to develop their own strategies to solve problems related to ratio and proportion.

In the seventh session, inverse proportions were explored. The researcher aimed for the students to solve the problems using the ratio information without 
teaching them the definition of direct proportions. In order to establish the relationship between direct and inverse proportions without giving the information to the students directly, a problem about inverse proportions was given to the students and classroom discussion took place. During the discussion process, the researcher aimed to assess the students' reasoning processes rather than getting the correct answers to the problems. The following transcript is an excerpt from the class discussion of the seventh session:

R: In a garden there are apple trees, and the apples are gathered in 6 hours by 4 workers. Do you think the apples would be gathered by 2 workers in more time or less time?

Samet: Teacher, it will take longer because the number of people decreases.

Berk: The time will increase, because 4 people can do it faster. So, with only 2 people it will take longer.

$\boldsymbol{R}:$ So, what kind of a relationship do you think there is between the number of workers and the time in which the work is done?

Berk: One rises while the other decreases.

Mehmet: Yes, it is the opposite. Like a seesaw, someone goes up and someone goes down.

Fatih: Teacher, this is inverse proportion.

$\boldsymbol{R}$ : What sort of mathematical description can we make if we compare the problems that we have solved up to now (the inverse proportion example) and the present example, if we get it together?

Asll: If one of the given items increases while the other increases, it is direct proportion. If one of the given items decreases while the other increases, it is inverse proportion.

Looking at the sample discussion process that took place during the seventh session, it was observed that the students tried to understand inverse proportion by starting with their understanding of direct proportion. When looking at the process of establishing students' understanding of direct and inverse proportionality relationships, it was observed that they were able to justify the similarities and differences between the problem situations and the reasoning that arose from the problems in the previous sessions. The process of associating the concepts of direct and inverse proportion was followed by the inverse proportion problem given in the eighth session.

For the following problem, the students were asked to find out what kind of proportion it was, find a solution, and justify their answer.

Question: The diameter of a bicycle front tire is $30 \mathrm{~cm}$ and the diameter of the rear tire is $20 \mathrm{~cm}$. How many times does the front wheel rotate when the rear wheel rotates 62 times along a road? 
Figure 6. Student Responses to the Sample Problem from the Eighth Session

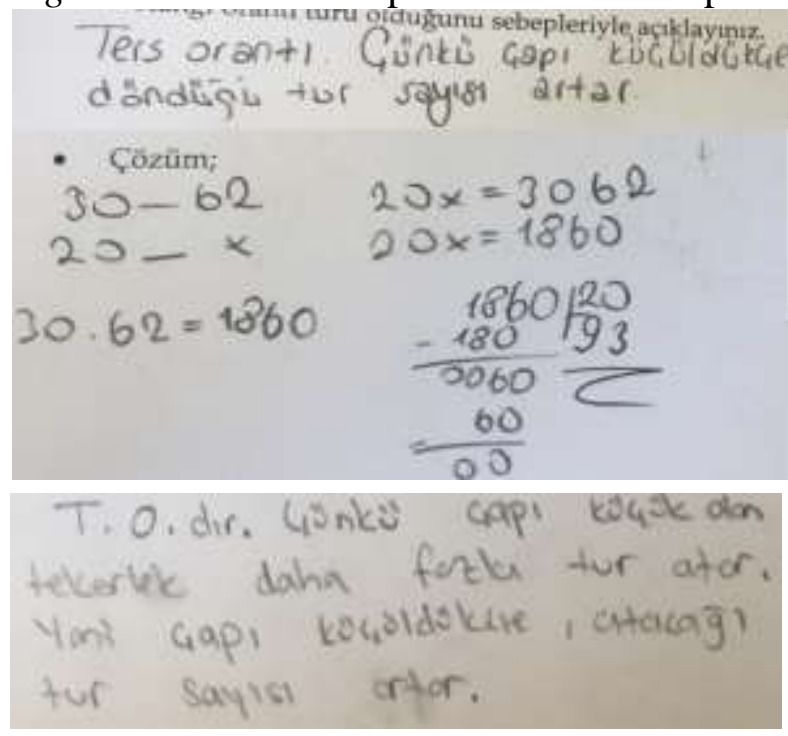

Upon examining the students' explanations in Fig. 6, it is clear that they determined the relationship between the variables using inverse proportions. When we look at the example mathematical solution, it seems that the solution is made by going beyond the cross-multiplication strategy used with direct proportions. The students who came up with the solution were asked to explain how they solved the problem and justify their ideas.

Burcu: In our previous examples, there was direct proportion, and some of our friends solved the problem of direct proportionality by doing crossmultiplication. For this question I thought like that, when we rate two things in the direct proportion, for example, we were writing 3 apples $/ 5$ oranges as the ratio of apples to oranges.

$\boldsymbol{R}$ : How would you like to express this in general terms, not just for the appleorange example?

Burcu: By using $a, b$, or something? If we want to rate two things, then we write $a / b$ so we can multiply and simplify the numerator and denominator with the same number. I thought it could be written as a product in the inverse proportion.

$\boldsymbol{R}:$ Why do you think the inverse can be expressed using multiplication?

Burcu: For example, we say in the direct proportion if 4 apples cost 5 liras, how much do 8 apples cost, we can write it like this 4/8=5/x. So, what is actually the same direct proportion between apple and price is written as 4 and 8 parts, so if there was an inverse proportion, the multiplication would be $4 x 8$.

$\boldsymbol{R}$ : It is not only for this example but also in general let us say, how you express there is an inverse proportion between two variables can be like the example that you gave.

Burcu: So, we can say a $x$ b if it is for any situation. 
$\boldsymbol{R}:$ Yes, it means that when expressing the direct proportion between the two expressions we can say $a / b$ and we can say $a x b$ when expressing the inverse proportion. Well, if you were going to describe the solution to the problem, why did you do side-by-side multiplication?

Burcu: Now if we write $4 / 8=5 / x$ we cross-multiply, if I generalize it as you wanted to be and if I write $a / b=c / d$, the cross product would be $a \times d=b \times d$. For the inverse ratio, I said a $x$ for the ratio display of two things. Then, $I$ can write $a \times b=c \times d$. That's what I did for the wheel; I wrote the wheel diameter times the number of turns. That is like $30 \times 62$, I can explain if it is not understood.

Looking at the solution of the student for the problem in the eighth session and his explanations, it seems that he has conceptually understood the relationship between direct proportion and inverse proportion. The student generalized and abstracted from the sample for the direct proportion, and also expressed the inverse proportion from the relation between the variables in the direct proportion at the same time. In the same way, for the inverse proportion, the student expressed himself using mathematical expressions correctly and making generalizations and abstractions independently of the sample case. It seems that the student has justified the explanations they have made and supported them with examples. The student stated that he/she could repeat his/her explanation, which shows that the student has the skill of persuasion.

The findings obtained from the interviews with the participants are consistent with those of the observations presented in Table 2. Reasoning, cause-effect relationship establishment, and reasoning and verification codes, which were obtained from the interview analysis, are presented alongside student statements.

Table 2. Reasoning Skill Scope of Student's Views

\begin{tabular}{|c|c|c|}
\hline Code & Participants & Sample Student' Answers \\
\hline \multirow{4}{*}{ 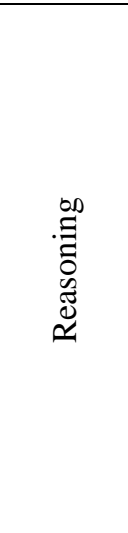 } & \multirow{4}{*}{$\begin{array}{l}\text { Aslı, } \\
\text { Berk, İdil, } \\
\text { Mehmet, } \\
\text { Samet }\end{array}$} & $\begin{array}{l}\text { Samet: Before, I did not know what ratio was, or what I needed to do. } \\
\text { But you showed different examples, such as lemonade and trucks, and I } \\
\text { learned about proportion from these questions. }\end{array}$ \\
\hline & & $\begin{array}{l}\text { Berk: In sixth grade, we were taught that "the comparison of two things } \\
\text { means that it is a division problem," but the first time this concept was } \\
\text { clear to me was when we were learning about proportion. }\end{array}$ \\
\hline & & $\begin{array}{l}\text { Idil: They make us memorize that "Cross-multiplying is for the direct } \\
\text { proportion, side-by-side multiplying is for the inverse proportion." But } \\
\text { for the first time in our class we saw why this happened, and I understood } \\
\text { why. }\end{array}$ \\
\hline & & $\begin{array}{l}\text { Asli: ...you did not give the definition of direct and inverse proportions } \\
\text { but when I saw the problem, I understood the relationship between } \\
\text { inverse and direct proportions. }\end{array}$ \\
\hline 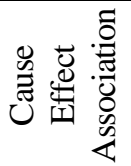 & $\begin{array}{l}\text { Ali, Burcu, } \\
\text { Fatih, } \\
\text { Mehmet, } \\
\text { Suna }\end{array}$ & $\begin{array}{l}\text { Mehmet: You asked for a question and all of us to solve it. You have } \\
\text { looked at our solutions from our individual notebooks. So, I solved the } \\
\text { questions forcibly. Because I do not know anyway, I thought } \\
\text { "how can I do this with what I know." }\end{array}$ \\
\hline
\end{tabular}




\begin{tabular}{|c|c|c|}
\hline & & $\begin{array}{l}\text { Fatih: We found that our friends were solving problems in different ways } \\
\text { and then they explained their solutions. When I see a question, I used my } \\
\text { mind, thinking "how shall I solve this, and which method is easiest?" }\end{array}$ \\
\hline \multirow{4}{*}{. } & \multirow{4}{*}{$\begin{array}{l}\text { Ali, Asli, } \\
\text { Burcu, } \\
\text { Samet, } \\
\text { Suna }\end{array}$} & $\begin{array}{l}\text { Suna: ...For example, if I solved the question on the board, I have to } \\
\text { explain my solution to my friends to convince them that I solved it } \\
\text { correctly. }\end{array}$ \\
\hline & & $\begin{array}{l}\text { Ali: Our solutions should have a logical explanation that we have solved } \\
\text { it correctly... }\end{array}$ \\
\hline & & $\begin{array}{l}\text { Samet: You say "why," when solving at the board, and sometimes I } \\
\text { realized that my solution did not make sense to me either and that it was } \\
\text { wrong. How do I know it's wrong? It is wrong if I cannot explain it or if } \\
\text { the solution path is not correct in mathematics. I cannot persuade my } \\
\text { friends if I cannot give them a good explanation. }\end{array}$ \\
\hline & & $\begin{array}{l}\text { Burcu: It's important to know the reason for something instead of just } \\
\text { memorizing. We forget when memorizing, and if we cannot explain why, } \\
\text { friends will not accept that method. I also do not believe something when } \\
\text { it is not explained to me. }\end{array}$ \\
\hline 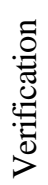 & Ali & Ali: I proved the correctness of the solution I made. \\
\hline
\end{tabular}

Therefore, it is clear that the IBL-M process had a positive effect on the students' reasoning skill. Upon examining the solutions given by students of different mathematical achievement levels, it seems that improvement in the reasoning skill of students at all levels occurred. In particular, students at lower mathematics achievement levels (i.e., Berk, Mehmet, and Samet) who struggled with multiplicative comparison in ratio and proportionality problems, were able to solve ratio problems using the unit rate strategy were able to solve ratio problems using the unit rate strategy. Students with moderate and high math achievement levels were able to make inferences, provide justification, and explain their reasoning. Furthermore, they were able to understand the cause-and-effect relationship between variables. These students also discovered effective fractional and cross-multiplication strategies and provided effective and persuasive explanations for their solutions. These findings were supported by student opinions and can be said to be positively influential in the development of reasoning skill, which are regarded as a basic skill required for ratio and proportion.

\section{Student Opinions of IBL in Mathematics Education}

The data obtained from interviews conducted to determine students' thoughts concerning IBL in mathematics education are presented in Table 3. Through the student interviews, the following codes were identified: positive attitude toward mathematics, discovery of different methods without giving rules, lack of 
memorization as a result of reasoning, and concretization. Table 3 presents these codes with direct student quotations.

Table 3. Student Opinions of IBL in Mathematics Education

\begin{tabular}{|c|c|c|}
\hline Code & Participants & Sample Responses \\
\hline \multirow{2}{*}{ 曾 } & \multirow[b]{2}{*}{$\begin{array}{l}\text { Mehmet, } \\
\text { Samet }\end{array}$} & Mehmet: I was afraid of math before, but this was more fun. \\
\hline & & $\begin{array}{l}\text { Samet: When I was able to develop my own method, I saw that I could } \\
\text { solve mathematics problems in my own way. }\end{array}$ \\
\hline \multirow{5}{*}{ 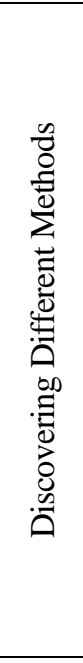 } & \multirow{5}{*}{$\begin{array}{l}\text { Ali, Asli, } \\
\text { Burcu, } \\
\text { Berk, } \\
\text { Fatih, İdil, } \\
\text { Mehmet, } \\
\text { Suna, } \\
\text { Samet }\end{array}$} & $\begin{array}{l}\text { Idil: Since you did not give us direct rules, we all tried to find solutions by } \\
\text { thinking and experimenting. }\end{array}$ \\
\hline & & $\begin{array}{l}\text { Suna: That we solved the problems as we wanted allowed us not to feel } \\
\text { restricted. When I encountered a problem, I saw that I could produce a } \\
\text { solution even though I did not know the rule. }\end{array}$ \\
\hline & & $\begin{array}{l}\text { Burcu: Normally in our lessons our teacher gives the rule and then we } \\
\text { solve the questions applying that rule. We learned afterwards what the } \\
\text { solution was when you were solving the questions in different ways. }\end{array}$ \\
\hline & & $\begin{array}{l}\text { Berk: After I solved each problem with you in different ways, when I } \\
\text { encountered a question, solutions that you made came to my mind. If it } \\
\text { makes it easier to solve the problem, I apply it. }\end{array}$ \\
\hline & & $\begin{array}{l}\text { Mehmet: Since in the lesson we did not learn the rule, we were forced to } \\
\text { solve the problems on our own. At first, I did not know what to do and it } \\
\text { was so difficult, but you wanted to bring all of us up to the board. I saw } \\
\text { where I did the right thing or wrong thing when I did my solutions. I do } \\
\text { not even try to solve any questions in our other lessons. }\end{array}$ \\
\hline \multirow{4}{*}{ 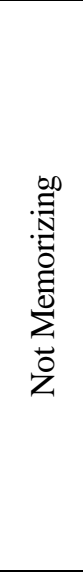 } & \multirow{4}{*}{$\begin{array}{l}\text { Berk, } \\
\text { Burcu, } \\
\text { Fatih, } \\
\text { Mehmet, } \\
\text { Suna }\end{array}$} & $\begin{array}{l}\text { Fatih: In the first lesson, you asked us what a ratio was, and you waited } \\
\text { for us to answer. Then we wrote all our answers and created the } \\
\text { definition of ratio ourselves. } \\
\text { We did not take the definition from a textbook. }\end{array}$ \\
\hline & & $\begin{array}{l}\text { Suna: Why we did something was very important. If I did not tell you why } \\
\text { I was doing something, my friends would not accept my method. }\end{array}$ \\
\hline & & $\begin{array}{l}\text { Burcu: You asked me why after you brought me up to the board to solve } \\
\text { a problem, which I thought was better. I can solve the problem by } \\
\text { understanding it as direct/inverse proportion, but I also learned the } \\
\text { reason for the numerations. I have not memorized the solution. }\end{array}$ \\
\hline & & $\begin{array}{l}\text { Berk: When my teacher told us the method, I kept it in my mind step by } \\
\text { step. I can solve most of the questions as well. But you gave me different } \\
\text { questions and you asked me and other friends why it is done like that. I } \\
\text { learned after hearing the explanations. }\end{array}$ \\
\hline \multirow{2}{*}{ 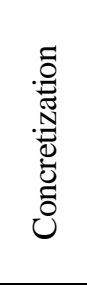 } & \multirow[t]{2}{*}{ İdil, Samet } & $\begin{array}{l}\text { Samet: You brought a lot of different materials to the course; they were } \\
\text { permanent in my mind. For example, you brought fruit to teach us ratio, } \\
\text { we talked about tall and short people, and we learned the unit /unitless } \\
\text { rates. }\end{array}$ \\
\hline & & $\begin{array}{l}\text { Idil: The use of pictures and the smart board was more colourful. It was } \\
\text { both memorable and visually pleasing. If we use the smart board, we can } \\
\text { see different kinds of problems, not just written questions. }\end{array}$ \\
\hline
\end{tabular}

The IBL-M implementation showed that the enriching teaching content appears to be effective in improving the learning outcomes of students. The results of the study showed that the students were challenged in the process that they were actively involved in, which fostered their positive attitudes toward mathematics and improved their confidence by making their own solutions. In light of these 
findings, it can be said that IBL-M has a positive effect on student reasoning skill, a finding that was reinforced by the students' opinions of the teaching method.

\section{Conclusions}

Reasoning skill is expressed by the NCTM (2000) as mathematical skills that must be developed at the beginning of primary education. It is stated that with the provision of reasoning skill development, it can also be effective in making proofs that are accepted as the basis for developing mathematical understanding in the upper grades (Stylianides, 2007). It has been stated that students often meet with difficulties in reasoning, ratiocinating, and generalization (Healy \& Hoyles, 2000; Healy \& Hoyles, 2007). For this purpose, it is possible to develop the elements of assumption, reasoning, and generalization as informal proof by the form of teaching that will be effective in the development of reasoning skill.

Reasoning skill is expressed by the NCTM (2000) as mathematical skills that must be developed at the beginning of primary education. It is stated that with the provision of reasoning skill development, it can also be effective in making proofs that are accepted as the basis for developing mathematical understanding in the upper grades (Stylianides, 2007). It has been stated that students often meet with difficulties in reasoning, ratiocinating, and generalization (Healy \& Hoyles, 2000; Healy \& Hoyles, 2007). For this purpose, it is possible to develop the elements of assumption, reasoning, and generalization as informal proof by the form of teaching that will be effective in the development of reasoning skill.

The findings of this study showed that by using the IBL-M, the students showed improvement in their reasoning skill, the inferences they made based on reasoning, and in developing and generalizing operational strategies using mathematical expressions. The students were able to produce solutions for real-life problems by solving problems through deductive and inductive reasoning based on their existing knowledge and experiences. It can be said that the IBL-M approach provides the opportunity for the identification, discovery, and development of students' reasoning skill. Similarly, Leatham, Peterson, Stockero, \& Zoest (2015) stated that IBL-M provides students with opportunities for rich forms of reasoning as part of classroom discourse in individual or small group work. The IBL-M approach requires students to make logical explanations for their solutions or provide justification for their answers by answering "why." It can be said that additive and multiplicative situations are learned by the students in this way. Proof can be given in informal ways, such as persuading their friends that their solution is correct. According to Wilhelm and Wilhelm (2010), IBL-M emphasizes that middle school students become effective at constructing and explaining their arguments. Likewise, Epstein (2007) found that adopting the IBL$\mathrm{M}$ approach in mathematics education can positively affect students' mathematical concept development, data collection techniques, data representation skills, and critical thinking skills. Rasmussen and Kwon (2007) found that IBL-M supports students' learning through mathematical discussions, explaining their thoughts, providing evidence, and using mathematical knowledge in different problems. 
Kuster, Johnson, Keene, \& Andrews-Larson (2017) reached the conclusion that IBL-M provides students with opportunities to generalize their existing knowledge through structuring and reasoning.

Schoenfeld (1996) stated that students should be able to answer questions through questioning. In the period of reasoning skill development, it is seen that students use different problem-solving strategies for realistic problems and explain their solutions using logical reasoning. Furthermore, it can be said that IBL-M is effective in developing students' critical and reflective thinking. Similarly, Pratt and Woods (2007), in the framework of the Postgraduate Certificate of Education (PGCE), stated that IBL-M is effective in developing problem-solving skills and mathematical reasoning, and fosters the creation of supportive learning environments. Studies have shown that questioning students allows them to better understand their solutions and contributes positively to the development of problem-solving skills (Chouinard, 2007; Mills et al., 2011).

The results of the present study were found to be based on the basic idea of mathematics by the students, followed by inquiry and reasoning, and mathematical language and demonstrations, and a formal development. In this context, as described by Rasmussen, Zandieh, and Wawro (2009), the mathematical terminology developed by IBL-M suggests that students' mathematical thinking and solutions contribute to the development of mathematical language, representation, and ideas that depend on certain mathematical standards. Jackson et al. (2013) emphasized the development of mathematical expressions and representations through the IBL-M approach, in which the expressions used by students in their solutions, mathematical ideas, and justifications are within the framework of certain mathematical norms.

In the present study, the students seemed to be more comfortable expressing themselves using mathematical language in IBL. They demonstrated confidence and were actively involved in the lessons. Previous research has demonstrated the positive effect on learning outcomes when students take an active role in the classroom (e.g., Polya, 2014; Schoenfeld, 1985; Schoenfeld, 1987). In addition, adopting the IBL approach in mathematics education was shown in this study to help develop students' positive attitudes toward mathematics and meaningful learning. This finding is consistent with the results of Wilhelm and Wilhelm (2010), who found that middle school students who were reluctant to participate in classroom activities, became more willing to do so in an IBL teaching environment.

Stein et al. (2008) stated that getting students to take active roles in the classroom is among the most challenging aspects of teaching. Stein et al. (2008) found that IBL in mathematics education is effective in ensuring that students participate in class and that students are actively involved in learning activities. Stephan and Rasmussen (2002) emphasized that IBL provides an environment in which students can share important mathematical ideas and ways of reasoning through individual or group work. Similarly, Kuster et al. (2017) suggested that students are encouraged to think about alternative approaches and ways of thinking in the IBL process, and that student skills and achievement development 
are supported, where opportunities for mathematical expression of students' views are provided.

Among the goals of the MoNE (2013) Middle School Mathematics Curriculum, it is stated that opportunities for students to be active in the teaching environment, conduct research and inquiry, think critically and justify, develop different solutions for problems, and express their opinions and thoughts should be encouraged. Based on the findings of the present study, it can be said that these goals can be achieved though the IBL-M approach. Thus, it can be said that the use of the IBL-M approach in mathematics education will contribute positively to the reasoning skill development of the students, among many other benefits. Based on findings of the present study, IBL-M should be investigated in different subjects and contexts to further investigate its effects. By examining the effect of IBL-M on different skills, the general applicability and effectiveness of the method can be demonstrated.

\section{Recommendations}

As a result of the study, recommendations for researchers and educators are presented below.

- IBL can be included in secondary school mathematics education. In this way, students are made more active and a positive effect can be achieved on both their math achievement and motivation.

- IBL-M was applied to ratio and proportion in this study. Studies on different mathematical subjects can also be carried out. Likewise, this study focused on students' reasoning skills in the IBL-M process. Comparisons can be made for mathematics skills thanks to the work to be done on different skills.

- Since this study is a qualitative research, the IBL-M process on ratio and proportion has been described in detail. In this way, it is thought that the content is useful and applicable for students with similar features. In addition, it is thought that contribution can be made to practitioners with the contents of IBL-M to be realized by different researchers.

\section{References}

Baron, J. (2010). Using a design challenge to teach proportion: 6th graders construct their dream classrooms. (Master's thesis). Hofstra University, New York.

Blair, A. (2008). Inquiry teaching. Mathematics Teaching Incorporating Micromath, 211, $8-11$.

Bogdan, R. C., \& Biklen, S. K. (1998). Qualitative research for education: An introduction to theory and methods. Needham Heights, MA: Allyn and Bacon.

Brown, S. I., \& Walter, M. I. (Eds.). (2014). Problem posing: Reflections and applications. Hillsdale, NJ: Erlbaum.

Chapman, O. (2011). Elementary school teachers' growth in inquiry-based teaching of mathematics. ZDM, 43(6-7), 951-963. 
Chouinard, M. M. (2007). Children's questions: A mechanism for cognitive development: IV. Children's questions about animals. Monographs of the Society for Research in Child Development, 72(1), 58-82.

Creswell, J. W. (2008). Educational research planning, conducting and evaluating quantitative and qualitative research. Boston: Pearson.

Engeln, K., Euler, M., \& Maass, K. (2013). Inquiry-based learning in mathematics and science: A comparative baseline study of teachers' beliefs and practices across 12 European countries. ZDM, 45(6), 823-836.

Epstein, A. S. (2007). The intentional teacher. Choosing the best strategies for young children's learning. Washington, DC: National Association for the Education of Young Children.

Fraenkel, J. R., \& Wallen, N. E. (2009). The nature of qualitative research. How to design and evaluate research in education. Boston: McGraw-Hill.

Guba, E. G., \& Lincoln, Y. S. (1982). Epistemological and methodological bases of naturalistic inquiry. Educational Communication and Technology Journal, 30(4), 233-252.

Hähkiöniemi, M. (2013). Teacher's reflections on experimenting with technologyenriched inquiry based mathematics teaching with a preplanned teaching unit. The Journal of Mathematical Behavior, 32(3), 295-308.

Handal, B. (2003). Teachers' mathematical beliefs: A review. The Mathematics Educator, 13(2), 47-58.

Healy, L., \& Hoyles, C. (2000). A study of proof conceptions in algebra. Journal for Research in Mathematics Education, 31(4), 396-428.

Healy, L., \& Hoyles, C. (2007). Curriculum change and geometrical reasoning. In P. Boero (Ed.), Theorems in school (pp. 81-115). Rotterdam: Sense Publishers.

Ilany, B., Keret, Y., \& Ben-Chaim, D. (2004). Implementation of a model using authentic investigative activities for teaching ratio and proportion in preservice teacher education. Proceedings of the 28th Conference of the International Group for the Psychology of Mathematics Education (vol. 3, 81- 88). Norway: Bergen University College.

Jackson, K., Garrison, A., Wilson, J., Gibbons, L., \& Shahan, E. (2013). Exploring relationships between setting up complex tasks and opportunities to learn in concluding whole-class discussions in middle-grades mathematics instruction. Journal for Research in Mathematics Education, 44(4), 646-682.

Jacobs, J. K., Hiebert, J., Givvin, K. B., Hollingsworth, H., Garnier, H., \& Wearne, D. (2006). Does eighth-grade mathematics teaching in the United States align with the NCTM Standards? Results from the TIMSS 1995 and 1999 video studies. Journal for Research in Mathematics Education, 37(1), 5-32.

Kasmer, L., \& Kim, O. K. (2011). Using prediction to promote mathematical understanding and reasoning. Mathematical Understanding and Reasoning, 11(1), 20-33.

Keselman, A. (2003). Supporting inquiry learning by promoting normative understanding of multivariable causality. Journal of Research in Science Teaching, 40(9), 898-921.

Kuster, G., Johnson, E., Keene, K., \& Andrews-Larson, C. (2017). Inquiry-oriented instruction: A conceptualization of the instructional principles. Problems, Resources, and Issues in Mathematics Undergraduate Studies (PRIMUS), 28(1), 13-30.

Kwon, O. N., Park, J. H., \& Park, J. S. (2006). Cultivating divergent thinking in mathematics through an open-ended approach. Asia Pacific Education Review, 7(1), $51-61$.

Lanius, C. S., \& Williams, S. E. (2003). Proportionality: A unifying theme for the middle grades. Mathematics Teaching in the Middle School, 8(8), 392-396. 
Leatham, K. R., Peterson, B. E., Stockero, S. L., \& Zoest, L. R. V. (2015). Conceptualizing mathematically significant pedagogical opportunities to build on student thinking. Journal for Research in Mathematics Education, 46(1), 88-124.

Martin, G., \& Kasmer, L. (2010). Reasoning and sense making. Teaching Children Mathematics, 16(5), 284-291.

Mercier, H., \& Sperber, D. (2009). Intuitive and reflective inferences. In J. Evans \& K. Frankish (Eds.), Two minds (pp. 149-170). New York: Oxford University Press.

Ministry of National Education (MoNE). (2009). Ilkögretim Matematik Dersi (6-8. Sinfflar) Ögretim Programı [Elementary Mathematics Educational Program (6th-8th Grades)]. Ankara: MEB Yayınları.

Ministry of National Education (MoNE). (2013). Ortaokul Matematik Dersi (5, 6, 7. ve 8 . Sinfflar) Öğretim Programı [Middle School Mathematics Educational Program (5th8th Grades)]. Ankara: Talim Terbiye Kurulu Başkanlığı.

Mills, C. M., Legare, C. H., Grant, M. G., \& Landrum, A. R. (2011). Determining who to question, what to ask, and how much information to ask for: The development of inquiry in young children. Journal of Experimental Child Psychology, 110(4), 539560.

National Council of Teachers of Mathematics (NCTM). (2000). Principles and standards for school mathematics. Reston, VA: National Council of Teachers of Mathematics.

National Council of Teachers of Mathematics (NCTM). (2009). Focus in high school mathematics: Reasoning and sense making. Reston, VA: National Council for Teachers of Mathematics.

Polya, G. (2014). How to solve it: A new aspect of mathematical method. Princeton: Princeton University Press.

Pratt, N., \& Woods, P. (2007). Changing PGCE students 'mathematical understanding through a community of inquiry into problem solving. Research in Mathematics Education, 9(1), 79-94.

Rasmussen, C., \& Kwon, O. N. (2007). An inquiry-oriented approach to undergraduate mathematics. The Journal of Mathematical Behavior, 26(3), 189-194.

Rasmussen, C., Zandieh, M., \& Wawro, M. (2009). How do you know which way the arrows go? The emergence and brokering of a classroom mathematics practice. In W. M. Roth (Ed.), Mathematical representations at the interface of the body and culture. Charlotte: Information Age Publishing.

Schoenfeld, A. H. (1985). Making sense of "out loud" problem-solving protocols. The Journal of Mathematical Behavior, 4(2), 171-191.

Schoenfeld, A. H. (1992). Learning to think mathematically: Problem solving, metacognition, and sense making in mathematics. In D. A. Grouws (Ed.), Handbook of research on mathematics teaching and learning (pp. 334-370). New York: MacMillan.

Schoenfeld, A. H. (1996). In fostering communities of inquiry, must it matter that the teacher knows "The answer." For the Learning of Mathematics, 16(3), 11- 16.

Schoenfeld, A. H. (Ed.). (1987). Cognitive science and mathematics education. Publishing location: Psychology Press.

Shield, M. J., \& Dole, S. (2008). Proportion in middle-school mathematics: It's everywhere. The Australian Mathematics Teacher, 64(3), 10-15.

Slavit, D., \& Lesseig, K. (2016). The development of teacher knowledge in support of student mathematical inquiry. Problems, Resources, and Issues in Mathematics Undergraduate Studies (PRIMUS), 27(1), 58-74.

Sperber, D. (2000). Metarepresentations in an evolutionary perspective. In D. Sperber (Ed.), Metarepresentations: A multidisciplinary perspective (pp. 117 - 37). Oxford University Press. 
Stein, M. K., Engle, R. A., Smith, M. S., \& Hughes, E. K. (2008). Orchestrating productive mathematical discussions: Five practices for helping teachers move beyond show and tell. Mathematical Thinking and Learning, 10(4), 313-340.

Stephan, M., \& Rasmussen, C. (2002). Classroom mathematical practices in differential equations. The Journal of Mathematical Behavior, 21(4), 459-490.

Stylianides, A. J. (2007). Proof and proving in school mathematics. Journal for research in Mathematics Education, 40(3), 289-321.

Stylianides, G. J., \& Stylianides, A. J. (2009). Facilitating the transition from empirical arguments to proof. Journal for Research in Mathematics Education, 40(3), 314-352.

Tourniaire, F., \& Pulos, S. (1985). Proportional reasoning: A review of the literature. Educational Studies in Mathematics, 16(2), 181-204.

Van de Walle, J. A., Karp, K. S., \& Bay-Williams, J. M. (2013). Elementary and middle school mathematics: Teaching developmentally, (8th Edition). Boston: Pearson Prentice Hall.

Wilhelm, J. D., \& Wilhelm, P. J. (2010). Inquiring minds learn to read, write, and think: Reaching all learners through inquiry. Middle School Journal, 41(5), 39-46.

Yıldırım, A., \& Şimşek, H. (2013). Sosyal bilimlerde nitel araştırma yöntemleri [Qualitative research methods in the social sciences]. (9. baskl). Ankara: Seçkin Yayınevi.

\section{Appendix-1: Individual Interview Form}

This interview aims to acquire information about your opinions on the practices and the content of IBL-M in which you participated. For this purpose, I will pose some specific questions. During the interview, your identity and your statements will be kept completely confidential. I guess it will take approximately 15 minutes to complete our interview. I would like to start the interview with your permission.

\section{Questions}

1. Can you evaluate the IBL-M process?

2. What are the positive/negative aspects?

3. What opportunities did it provide?

4. Do you want your other lessons/subjects to be conducted with this method? 